\title{
LABORATORY EXPERIMENTATION COMPARISON OF CENTRIFUGAL CASTING MACHINES FOR DUCTILE CAST IRON PIPES
}

\author{
Mohamed A. Shehata ${ }^{1}$, Saad Kassem ${ }^{2}$ and Ahmed Bahgat ${ }^{3}$ \\ ${ }^{1}$ El Nasr Casting Company, Egypt \\ ${ }^{2}$ Department of Mechanical Design and Production, Cairo university, \\ ${ }^{3}$ Department of Electrical power and machines Cairo university
}

\begin{abstract}
Centrifugal casting machines are a production machines used to produce ductile cast iron pipes in the casting method in El Nasr Casting Company. The Casting Machines were manufactured by Thyssen Rheinstahl Technik GmbH. They are usually driven by three-phase separately excited DC motor of a nominal voltage of $400 \mathrm{~V}$ and nominal power $222 \mathrm{~kW}$. Lower overall efficiency leads to higher electricity consumption [1].

Motor performance characteristics and control strategies are described for both AC and DC machines ,However, with advances in AC motor drives (vector flux variable frequency drives) their dynamic response has improved dramatically, making them an attractive alternative to DC drive systems. Due to improved dynamic response and better motor efficiency of AC drives (compared to DC drives), centrifugal casting machines using AC drives can run faster than using DC drives, resulting in improved productivity and significant electrical energy savings.
\end{abstract}

\section{INTRODUCTION}

This papers presents details of the Laboratory Experimentation study simulating of centrifugal casting machine for producing $6000 \mathrm{~mm}$ long ductile cast iron pipes of the nominal diameters DN1000. The production process was carried out on a centrifugal casting machine, which is described in detail in section 2. In this process the ductile cast iron pipes are deformed by centrifugal casting machines. The process parameters were set by the operator desk and measured during deformation, and then compared to those calculated theoretically. Pipes made of ductile cast iron were used in the centrifugal casting machines process.

DC drive systems have been the preferred technology to drive centrifugal casting machines. DC motors are able to maintain a relatively constant shaft speed, regardless of any load torque variation, which helps control the quality of the ductile cast iron pipe thickness.

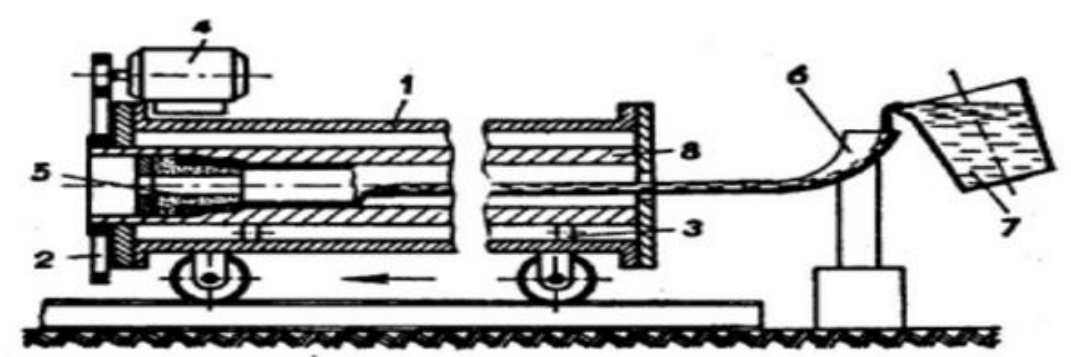

Fig. 1 centrifugal casting machine assembly production line [1] 


\section{PROCESS DESCRIPTION}

From figure1,the pouring pot (7) is filled with liquid iron from the casting ladle up to the overflow. At the same time the core setting device is equipped with a socket core and the socket area of the mold is charged with scatter material. After the start release is given by the pouring desk and the control desk, the core setter swings in and presses the core against the core position of the mold. At the same time the mold drive motor (4) starts and The revolution speed ramp increase from 0 to $450 \mathrm{rpm}$ from time 0 to 15 seconds Fig. 4 the mold carriage begins the upward travel, The travelling speed ramp increase from 0 to $300 \mathrm{~mm} / \mathrm{s}$ from time 0 to 5 seconds Fig. 5 while the scattering device is in operation. Before the uphill position is reached, the pouring pot starts tilting, the injection device charges inoculants, and the slagfree iron runs into the runner inlet and into the runner (6). As soon as the iron flowing through the mold (8)has filled the socket while the mold carriage (1) is standing, the mold carriage begins the casting travel at constant revolution speed $450 \mathrm{rpm}$ until time 70 seconds Fig. 4 and constant travelling speed of mold carriage $300 \mathrm{~mm} / \mathrm{s}$ until time 70 seconds Fig. 5. During the casting travel, the injection device feeds inoculants before the iron jet into the mold. At the end of the pouring pot tilting period, which depends on the nominal diameter, the pot tilts back, and the injection device is switched off. As the iron jet becomes continuously weaker, the mold carriage traveling speed becomes correspondingly slower $10 \mathrm{~mm} / \mathrm{s}$ Fig.5, while the number of mold revolutions increases to $500 \mathrm{rpm}$ until time 85 seconds Fig. 5 .

When the rest of the iron has flown into the mold at the spigot end, the scattering device is switched off, and the mold carriage goes downhill at increased speed to $300 \mathrm{~mm} / \mathrm{s} \mathrm{Fig.} \mathrm{5.} \mathrm{The}$ mold revolution speed is reduced to the cooling speed $350 \mathrm{rpm}$ Fig. 4. At the end of the cooling period, which depends on the nominal diameter DN1000, the core setting device swings out, and the pipe can be drawn out. The drawing and rolling off of the pipe from the drawing line are carried out automatically [1].

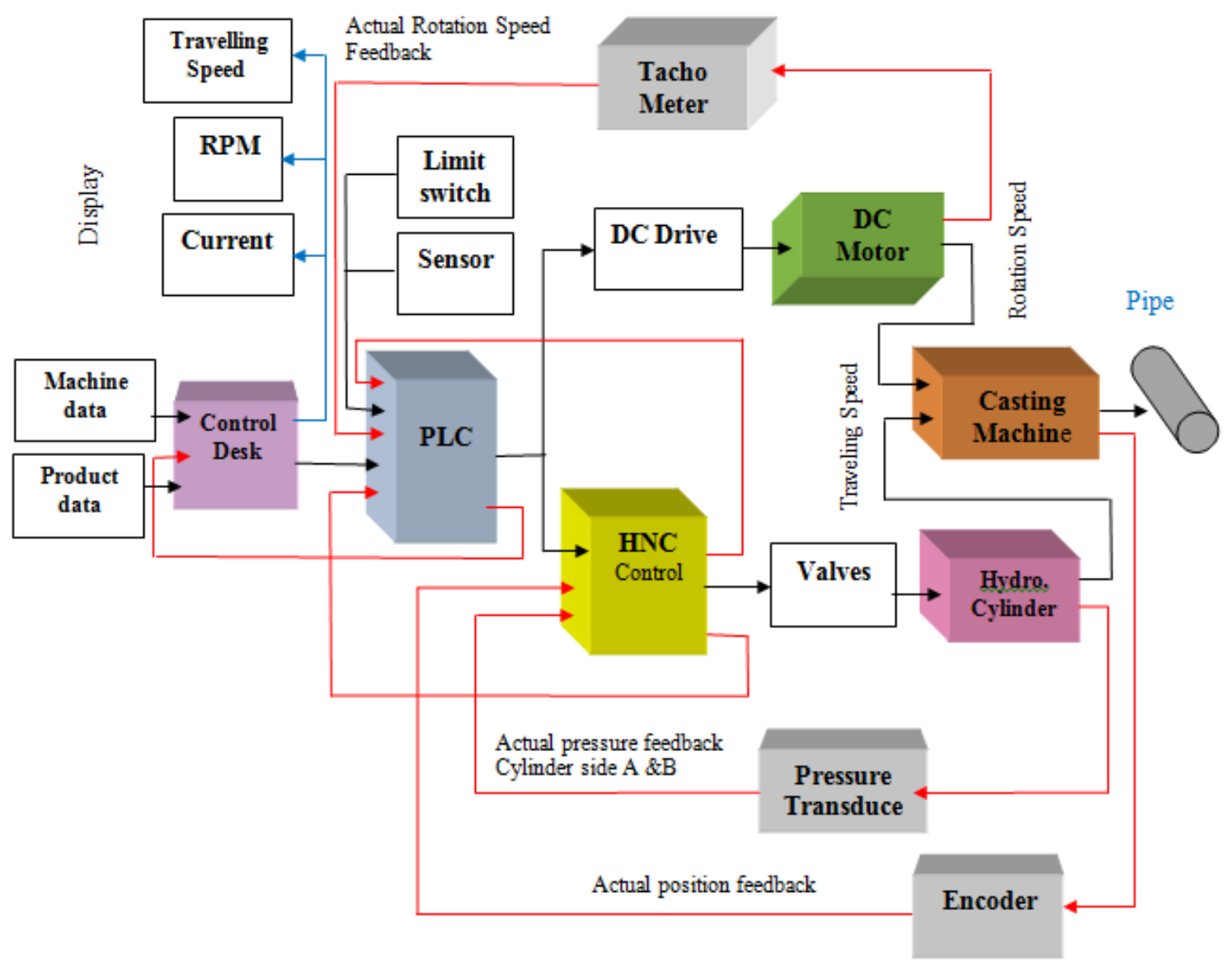

Fig.2 Block diagram of flow signal control 


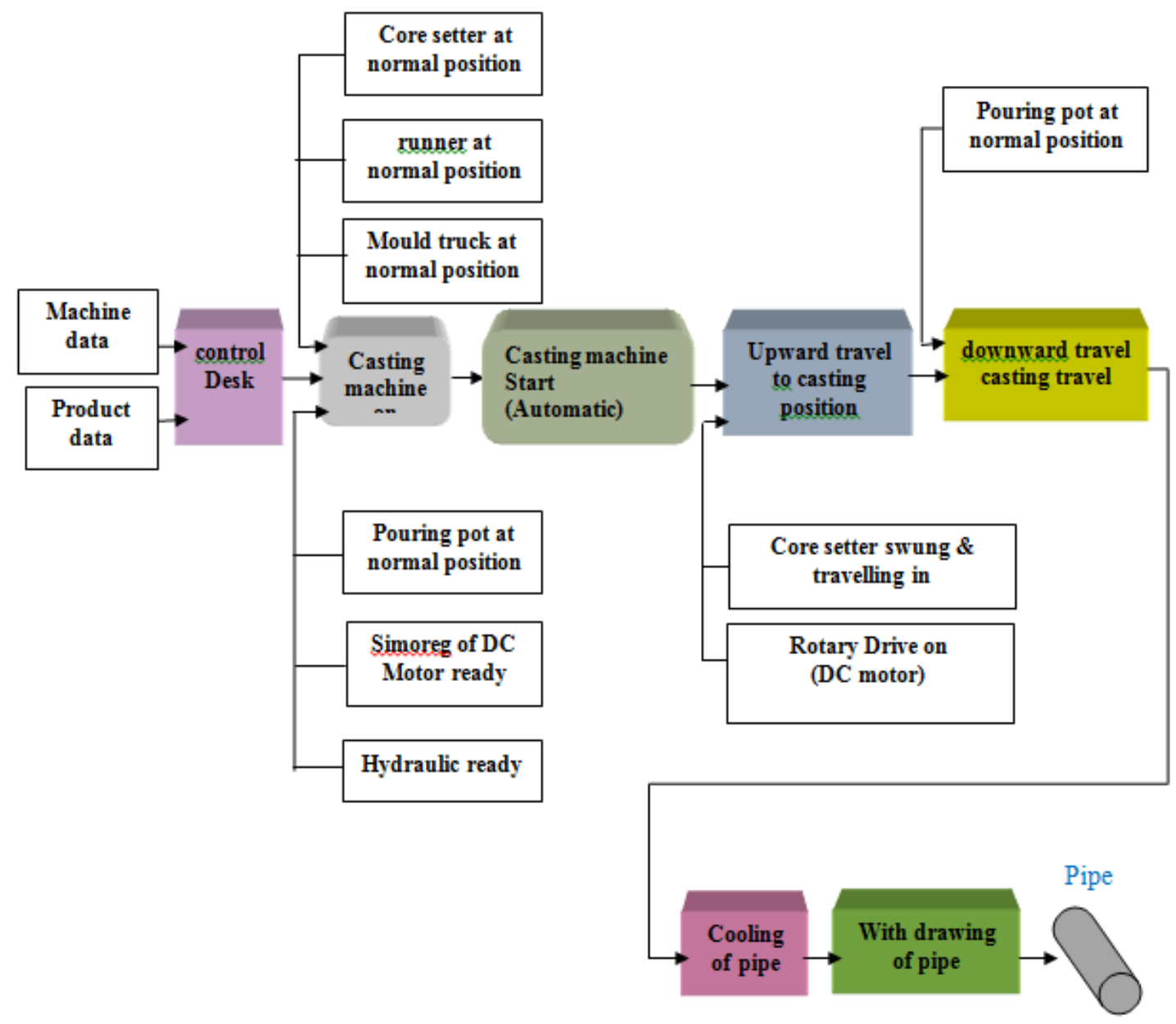

Fig. 3. Block diagram of process steps.

\section{MACHINE PERFORMANCE DATA}

\subsection{Revaluations speed}

Table 1 casting revolution speed values for pipe size DN1000[1].

\begin{tabular}{|l|c|}
\hline DN $(\mathbf{m m})$ & $\mathbf{1 0 0 0}$ \\
\hline Casting speed(rpm) & 450 \\
\hline Spigot end (rpm) & 500 \\
\hline Cooling speed (rpm) & 350 \\
\hline Drawing speed (rpm) & 10 \\
\hline
\end{tabular}




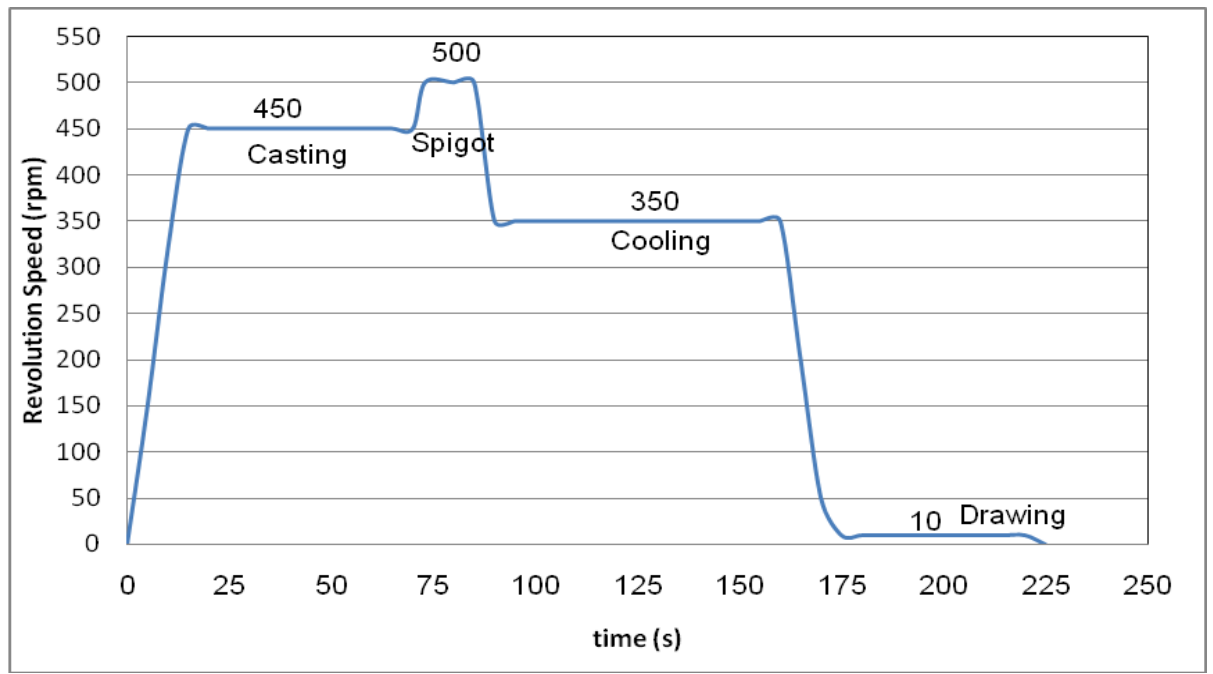

Fig. 4 Revolution speed vs. casting time along pipe length[1]

From time 0 to 15 seconds The revolution speed ramp increase from 0 to $450 \mathrm{rpm}$ (casting speed of ductile iron pipe shaft DN1000), this speed is constant until time 70 seconds, then The revolution speed ramp increase from 450 to $500 \mathrm{rpm}$ (casting speed of ductile iron pipe spigot DN1000), this speed is constant until time 85 seconds, the speed ramp lowered to 350 rpm (cooling speed of ductile iron pipe DN1000), this speed is constant until time 125 seconds, the speed ramp lowered to $10 \mathrm{rpm}$ (drawing speed of ductile iron pipe DN1000), this speed is constant until time 225 seconds and the speed ramp lowered to $0 \mathrm{rpm}$.

\subsection{Traveling speed}

Table 2. Casting traveling speed values for pipe size DN1000 [1].

\begin{tabular}{|l|c|}
\hline DN $(\mathbf{m m})$ & $\mathbf{1 0 0 0}$ \\
\hline Travelling Casting speed $(\mathrm{m} / \mathrm{s})$ & 0.3 \\
\hline Creeping speed $(\mathrm{m} / \mathrm{s})$ & 0.1 \\
\hline Spigot end $(\mathrm{m} / \mathrm{s})$ & 0.3 \\
\hline Cooling speed $(\mathrm{m} / \mathrm{s})$ & 0 \\
\hline Drawing speed $(\mathrm{m} / \mathrm{s})$ & 0 \\
\hline
\end{tabular}

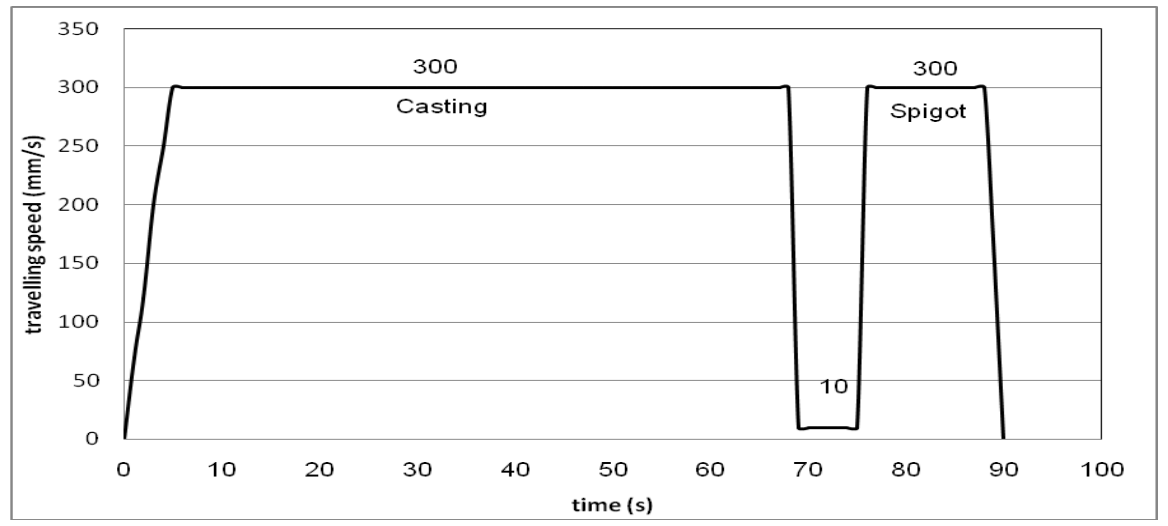

Fig. 5. Practical Travelling speed vs. casting time for DN1000 along pipe length[1]. 
From time 0 to 5 seconds The travelling speed ramp increase from 0 to $300 \mathrm{~mm} / \mathrm{s}$, (travelling speed of ductile iron pipe shaft DN1000), this speed is constant until time 70 seconds, the speed ramp lowered to $10 \mathrm{~mm} / \mathrm{s}$ (creeping speed) and this speed is constant until time 75 seconds, then the speed ramp increase to $300 \mathrm{~mm} / \mathrm{s}$ (travelling speed of ductile iron pipe spigot DN1000), this speed is constant until time 85 seconds, and the speed ramp lowered to 0 $\mathrm{mm} / \mathrm{s}$.

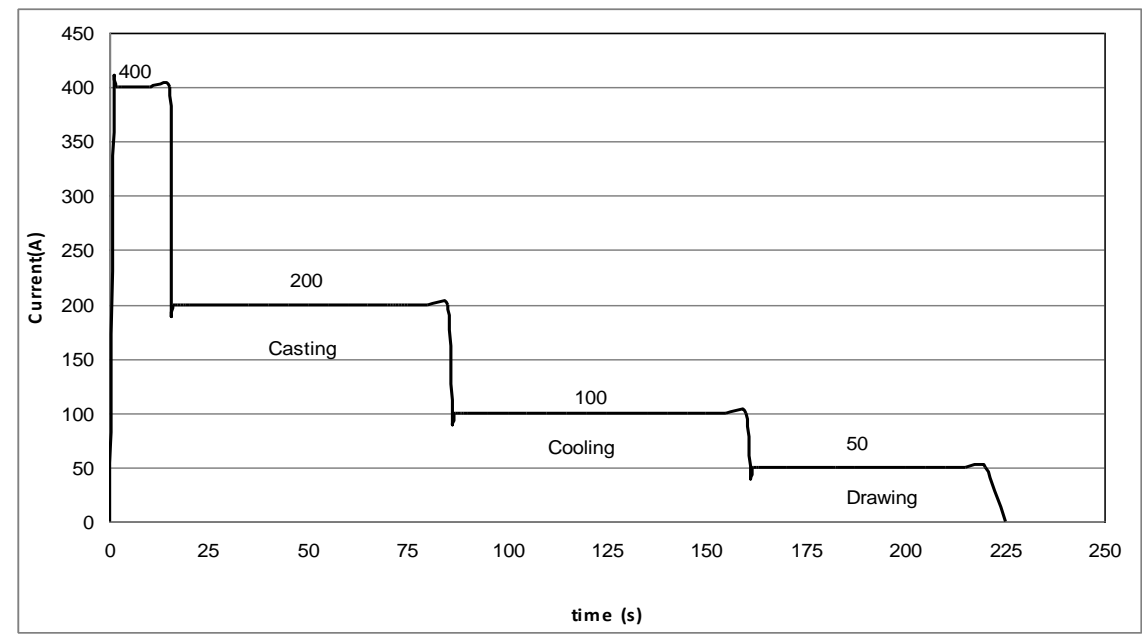

Fig. 6. Practical Current vs. casting time for DN1000 along pipe length[1].

The current ramp increases from 0 to $400 \mathrm{~A}$ (starting current), this current is constant until 15 seconds, the current ramp lowered to 200 A (casting of ductile iron pipe shaft and spigot DN1000), this current is constant until time 85 seconds, then the current ramp lowered to 100 A(cooling of ductile iron pipe DN1000), this current is constant until time 160 seconds, the current ramp lowered to $50 \mathrm{~A}$ (drawing of ductile iron pipe DN1000), this current is constant until time 225 seconds and the current ramp lowered to $0 \mathrm{~A}$.

\section{Experimental Set Up}

\subsection{Introduction}

The Virtual Instrumentation System is intended for use in Electrical Systems where a number of measuring instruments is generally required to evaluate the system behavior. Conventionally, this would be achieved using several separate bench meters, but now a personal computer (PC) and virtual instrumentation combines all these instrument functions. Software is used to reproduce the meter functions and provide a virtual instruments display [2].

\subsection{Machine Testing System}

The Virtual Instrumentation System operation is extended with the addition of the Torque/Speed Control Panel 68-441 and dynamometer. This addition to the Virtual Instrumentation System forms a complete Machines 


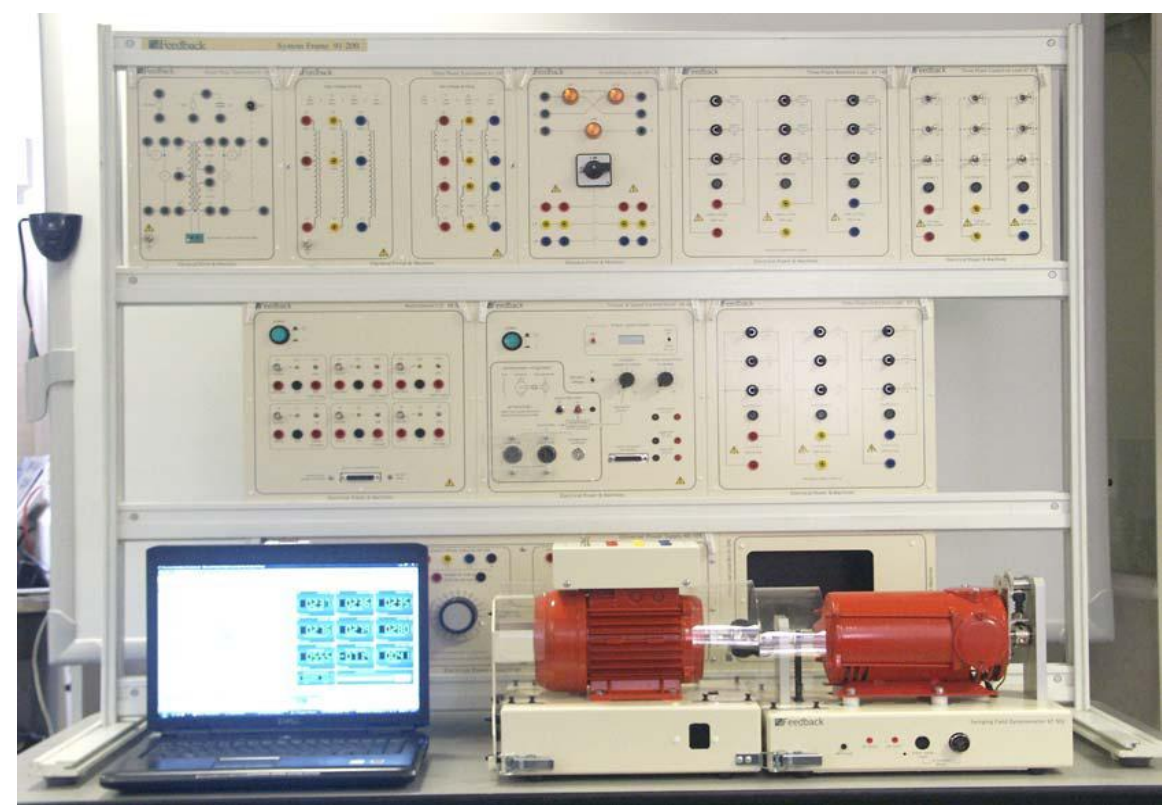

Fig. 7., Powerframes Components

Testing System as shown in Figure 6.

The complete system comprises:
Torque/Speed Control Panel
Dynamometer
Interconnecting Cables for Dynamometer
$68-441$
Multichannel I/O Unit 68-500-USB
Software Pack 68-912-USB.
] USB Interconnection Cable

The machine testing system is controlled by the virtual instrumentation software. The system software allows motor loading, as a torque quantity (Nm), to be set and varied from the computer, or a speed quantity ( $\mathrm{rpm})$ set and varied if the dynamometer is operated in speed mode.

Electrical input quantities and machine output parameters are monitored or measured using the Multichannel I/O Unit 68-500. Measurements of incoming supplies which consist of up to three voltages and three currents, are shown on virtual instrumentation displays on the computer screen. Additionally, the system can compute and display power, phase angles, power factors, volt-amperes and frequencies. To differentiate between the manually operated system and that which is PC controlled the manual system is called a Machines loading system and the PC controlled version the Machines testing system. 


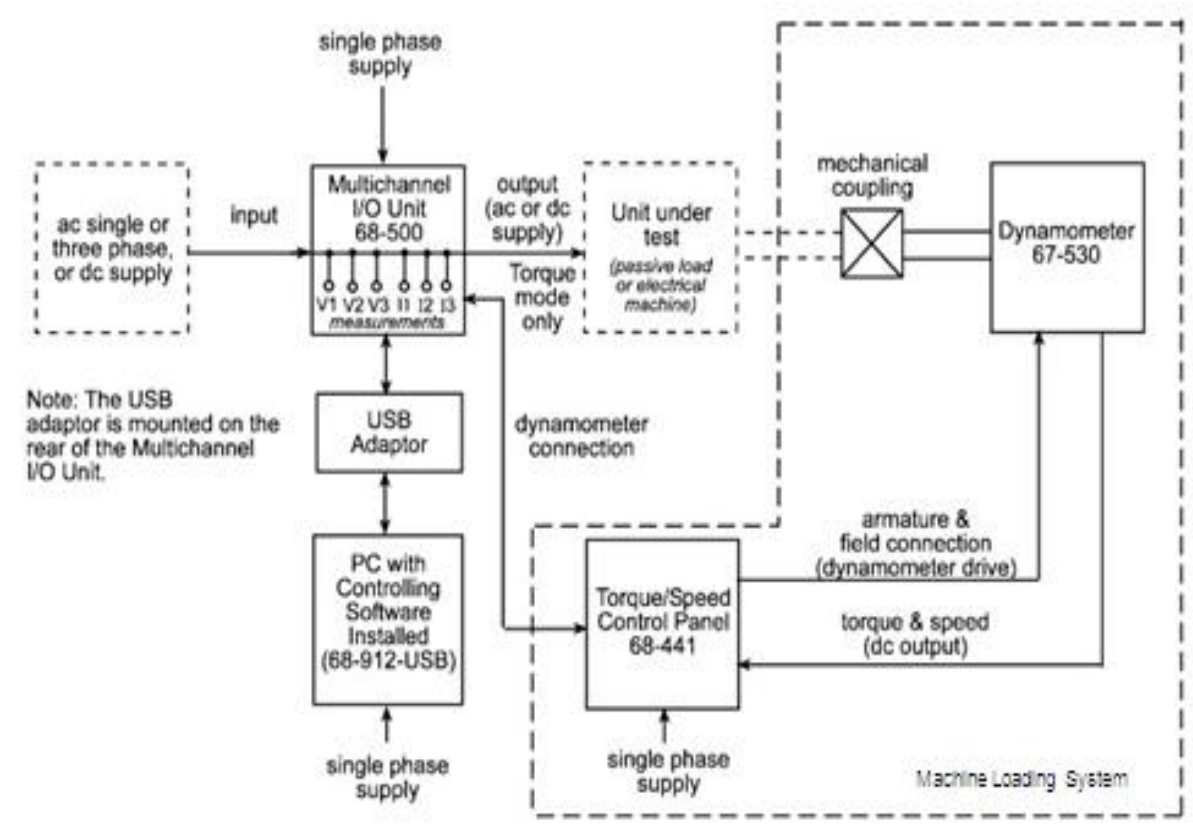

Fig. 8 Complete Machines Testing System [2].

\section{CIRCUIT DIAGRAMS AND WIRING FOR DC MOTOR}

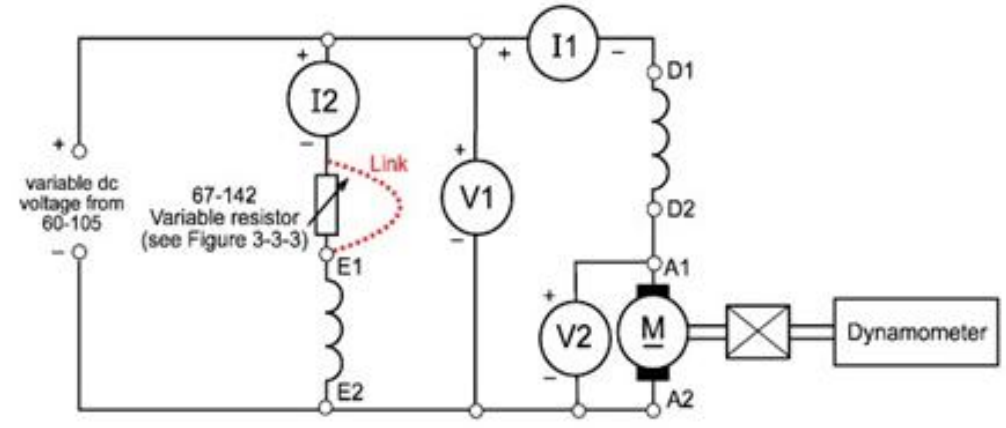

Fig. 9 Circuit Diagram for DC Motor [2].

\section{Circuit Diagrams and Wiring for AC Motor}

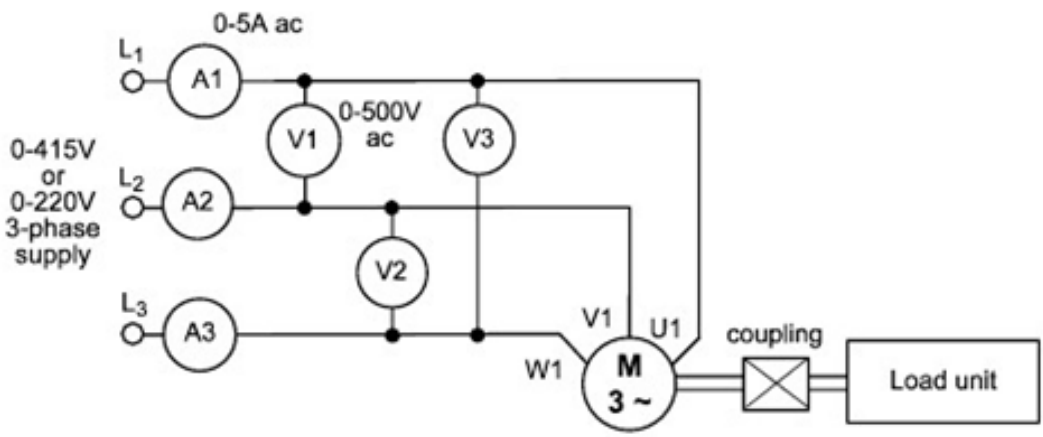

Fig. 10 Circuit Diagram for AC Motor [2].

\section{EXPERIMENTAL RESULTS}

\subsection{DC compound wound motor}

7.1.1 63-120 (220 Vdc - 300 VA)

Instrument No. : 63-120-230

Serial No. : ISN16085 
Rated at $250 \mathrm{~W}$ continuous.

Nominal speed 2,000 rev/min.

Maximum speed 6,000 rev/min.

Power requirement $220 \mathrm{~V}$ dc.

7.1.2 Manual Swinging Field Dynamometer 67-502

Permanently mounted dc Tachogenerator.

Speed: \pm 5000 rpm maximum

Torque: $\pm 3 \mathrm{Nm}$ maximum

7.2 AC- 3phase induction motor- Squirrel Cage,

7.2.1 Dual Voltage 64-501 (50HZ - 300 VA) [2]

Instrument No. : 64-501-230

Serial No. : ISN161370.

Dual voltage machine, 380/415V, Star 220/240V Delta.,,

Rated at $250 \mathrm{~W}$.

Rotates at up to $2980 \mathrm{rev} / \mathrm{min}$ at $50 \mathrm{~Hz}$.

Power requirement 380/415V, $50 \mathrm{~Hz}$,

Three Phase ac or $220 / 240$ V delta

\subsubsection{Manual Swinging Field Dynamometer 67-502}

Permanently mounted dc Tachogenerator.

Speed: $\pm 5000 \mathrm{rpm}$ maximum

Torque: $\pm 3 \mathrm{Nm}$ maximum

\subsubsection{ATV32HU22N4 - 2.2kW/3HP 380-500V ,5.5A[3]}

Schneider Electric software : Somov

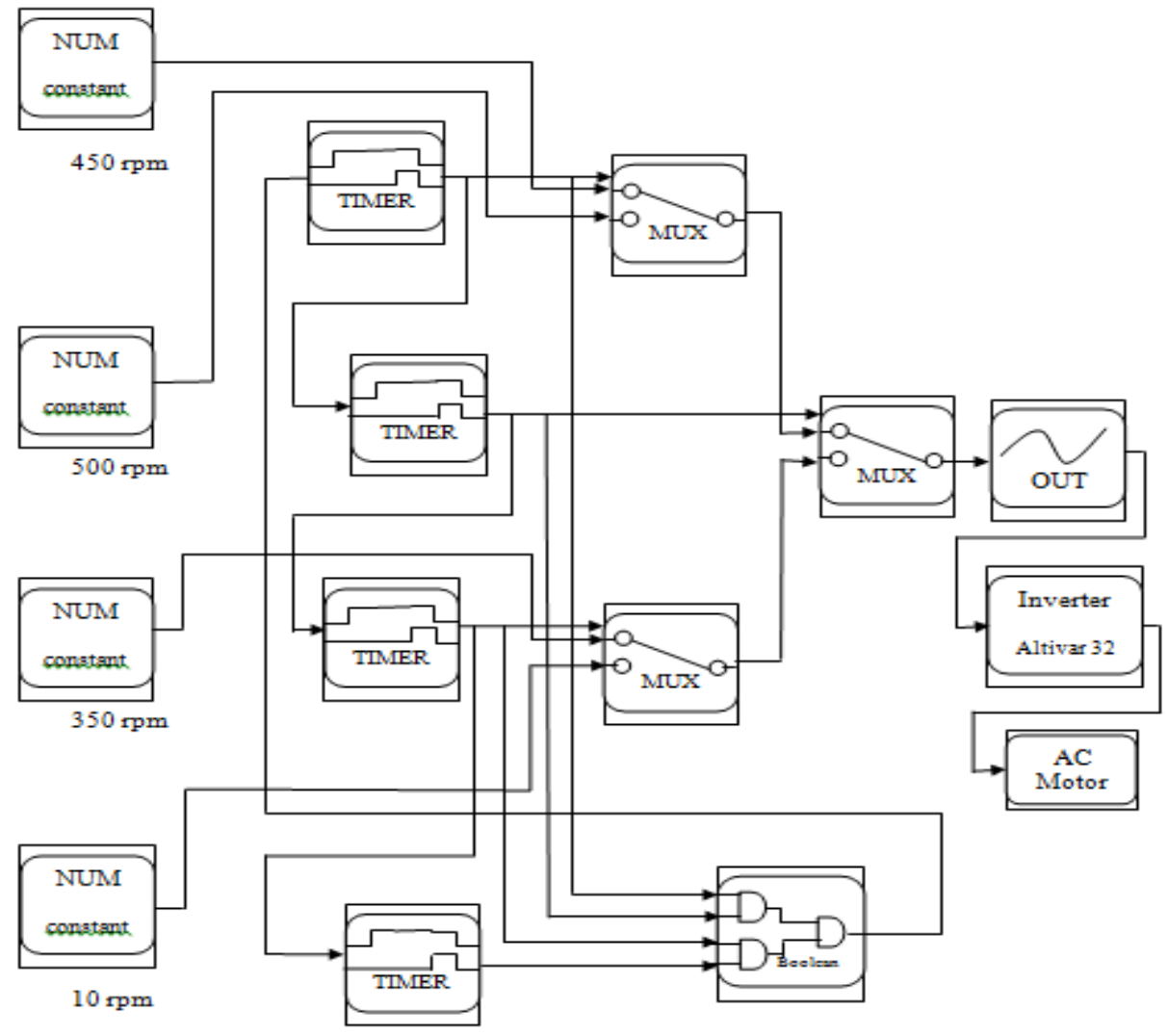

Fig. 11 Function block to create the speed set points by somov software (Speed curve of centrifugal casting machine) As inputs of AC drive (Altivar 32) 


\section{COMPARISON BETWEEN DC AND AC MOTOR PERFORMANCE}

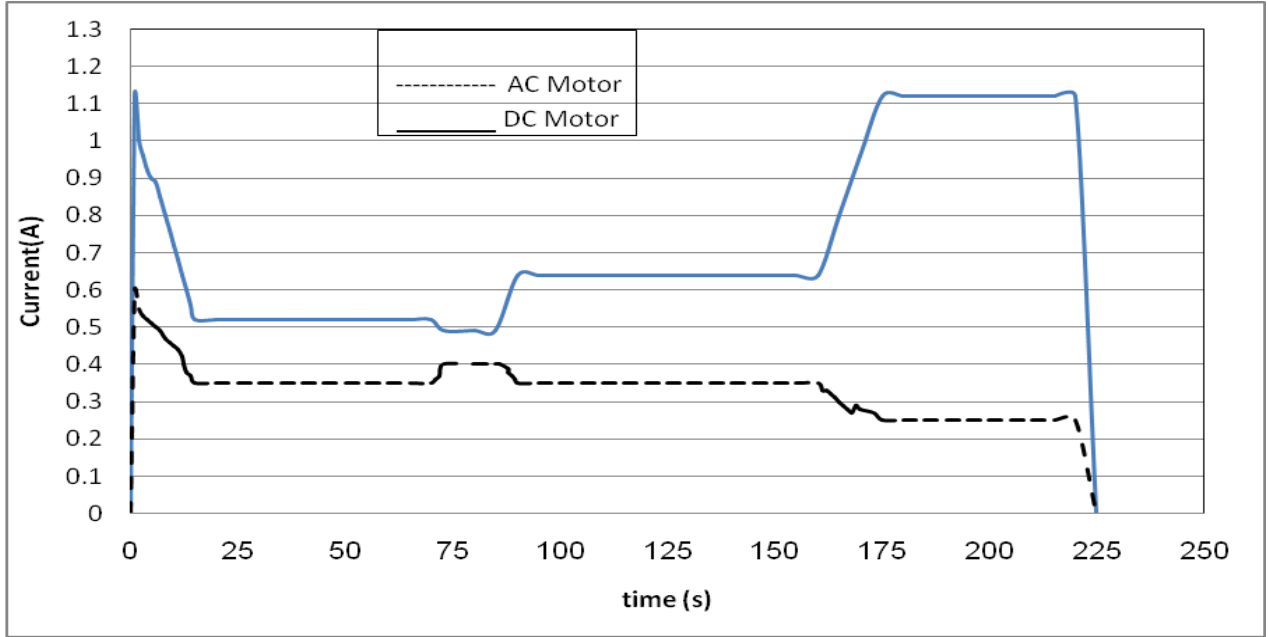

Fig. 12 Current vs. time for (AC induction motor) and (DC motor)

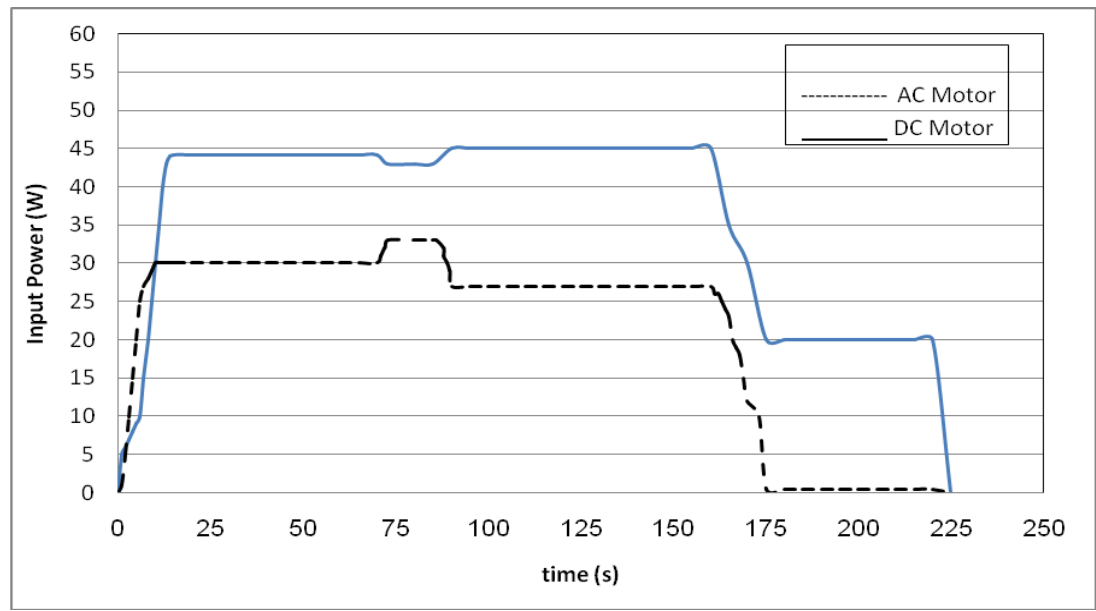

Fig. 13: input power vs. time for (AC induction motor) and (DC motor)

\section{ENERGY SAVINGS}

Speed curve of Centrifugal casting machine driven by a DC drive system Fig. 3 (speed of pipe DN1000 production) and laboratory simulation replacement DC motor $(250 \mathrm{~W})$ by an AC motor $(250 \mathrm{~W})$ at speed curve applied. The AC retrofit resulted in a significant reduction in total electrical energy consumption as well as an increase in productivity. Detailed electrical measurements (instantaneous revolution speed and current measurements) where performed on one of the centrifugal casting machine powered by a DC system. The simulating laboratory revolution speed, current drawn and input power, for the AC and DC driven for a period of 225 seconds (production time of pipe DN1000 production) is presented in Figures 12 and 13 above.

Some interesting features shown in Figures 12 and 13 are:

The AC drive requires less current (thus less power) to operate than the DC drive. On average the AC drive draws approximately $0.35 \mathrm{~A}$, while the $\mathrm{DC}$ drive draws approximately $0.85 \mathrm{~A}$.

Since replacing the DC drive system with an AC drive system resulted in a productivity improvement, comparing the electrical energy consumption before and after the retrofit requires normalizing the energy consumption versus product rate . 


\subsection{Anticipated Savings}

The electrical energy savings will be calculated by comparing the electrical energy consumption of the DC driven with that of the AC driven.

Approx. DC Power drawn:

$\mathrm{P}_{\mathrm{DC}}=0.0024306 \mathrm{KW} \mathrm{hr}$

Approx. AC Power drawn:

$\mathrm{P}_{\mathrm{AC}}=0.0014243 \mathrm{KW} \mathrm{hr}$

Approx. Power saving:

$\mathrm{P}_{\mathrm{sav}}=0.0024306-0.0014243=0.0010063 \mathrm{KW} \mathrm{hr}$

\section{CONCLUSION}

Replacing of DC motor with AC motor in centrifugal casting machines by laboratory simulation offering the following performance improvements as predicted from mathematical relations.

- Better control of motor speed, torque, and power

- Quick response to load changes

- Ability to provide max. torque at zero speeds

Since Replacing of DC motor with an AC motor in centrifugal casting machines by laboratory simulation, Due to higher energy efficiency of AC motors versus DC motors and the improved controls strategy, AC drive system retrofits can result in a significant electrical energy saving and productivity improvement of centrifugal casting machines. by lowering the energy consumption $(\mathrm{kWh})$. It is expected that an AC retrofit will result in an energy consumption reduction of approximately $40 \%$. In the above case study, the AC retrofit of the centrifugal casting machines saved approximately $0.0010063 \mathrm{kWh}$, It is expected that an AC retrofit will result in an energy intensity reduction.

\section{REFERENCES}

[1] Thyssen Rheinstahl Technik GmbH Documentations, DUSSELDROF/ GERMANY- El Nasr Casting Company, Egypt.

[2] power frames electrical machines Virtual Instrumentation pack manual 60-070- VIP

[3] Altivar 32 Variable speed drives for synchronous and asynchronous motors

Programming Manual, ATV32_programming_manual_S1A28692_0103/2010 